\title{
El derecho al pago del Seguro de Depósitos por el cierre de entidades financieras del sector popular y solidario en el Ecuador
}

\author{
Eduardo Paredes-Paredes'; Bryan Velaña-Bayas²
}

Fecha de recepción: 17 de Octubre 2018

Fecha de aceptación: 5 de Diciembre 2018

\section{Resumen}

El Estado ecuatoriano garantiza el derecho al pago del Seguro de Depósitos a todas las personas que fueron afectadas por el cierre (liquidación forzosa) de entidades financieras del sector popular y solidario; el cual, protege de forma limitada los depósitos efectuados en las entidades descritas, con el fin de que puedan recuperar sus ahorros conforme la ley. Se realiza un análisis de la normativa y de los procedimientos realizados por las entidades de control; y se determina que el ordenamiento jurídico, no contribuye a una eficiente devolución de los depósitos a los afectados, lo cual vulnera derechos y principios constitucionales.

Palabras clave: Seguro de depósitos, derecho, principio de eficiencia, administración pública.

\section{Abstract}

Ecuadorian State guarantees the right of the deposit insurance payment to every individual who was affected by the closure (Forced settlement) of financial entities of the popular and solidary sector; which protects deposits made in the entitites involved in a limited way with the aim of been able to recover their savings according to the law. An analysis of the norms and procedures made by control entities, it is also determined that the legal system does not contribute to an efficient return of deposits to those affected, which violates constitutional rights and principles.

\section{Keywords: Deposit insurance, rights, efficiency principle, public administration.}

\section{Introducción}

La presente investigación se la ha realizado por el impacto social y económico que ha generado el cierre de varias entidades financieras del sector popular y solidario en el Ecuador (cooperativas de ahorro y crédito). La importancia de éste estudio radica en determinar si el Estado está dando cumplimiento a lo establecido en el artículo 329 del Código Orgánico Monetario y Financiero respecto al derecho al pago del Seguro de Depósitos a todos los afectados del cierre de las entidades antes dichas; para lo cual se pretende establecer un procedimiento legal para una eficiente devolución de los dineros o fondos a los acreedores, socios, depositantes y cuenta ahorristas.

El trabajo contiene la conceptualización de temas como: el Seguro de Depósitos, Corporación del Seguro de Depósitos, Fondo de Liquidez y Fondo de Seguros Privados (COSEDE), Principio de eficiencia de la Administración Pública y también enfatiza la violación del derecho al pago del Seguro de Depósitos en el Ecuador mediante datos recabados del Catastro del Sector Financiero y la COSEDE, porque vulnera derechos y principios constitucionales.

Se han realizado investigaciones que guardan relación con el objeto de estudio, entre los más importantes se pueden enunciar: Cerna (2015), Navarro (2015), Ricaurte (2007), Garabiza (2014), Ipiales (2016); sin embargo, en el Ecuador no se han elaborado trabajos respecto a la temática principal.

Los organismos financieros privado, popular y solidario en caso de debilidad patrimonial pueden pagar a los acreedores en caso de liquidación (Cerna, 2015).

En nuestro país las entidades financieras (cooperativas de ahorro y crédito) sufrieron una crisis económica, lo cual afectó directamente a la dolarización, al régimen monetario como a los depositantes debi- do a las consecuencias de liquidez y solvencia de las entidades antes descritas (Navarro, 2015). Sin embargo, el mecanismo del seguro de depósitos o fondo de garantía fue un sistema de protección al ahorro con fin de establecer una seguridad dentro del sistema financiero: con características internacionales para que la ley sea más simple y clara posible (Ricaurte, 2007).

La COSEDE permite tutelar y brindar estabilidad económica y financiera a sus socios (Garabiza, 2014). Por ende, esta entidad antes mencionada determina una base de datos validada y depurada para efectuar el cumplimiento del derecho al pago del seguro de depósitos (Ipiales, 2016).

\section{Fundamentos Teóricos}

Seguro de Depósitos

En el Ecuador, dentro del Reglamento a la Ley Orgánica de Economía Popular y Solidaria (2018) se define que: El seguro de depósitos cubrirá los depósitos a la vista o a plazo fijo, realizados en las organizaciones del sector financiero popular y solidario, siempre que, se encuentren debidamente contabilizados como pasivos en dichas entidades y dentro de las condiciones determinadas en el presente reglamento y en las disposiciones emitidas por el directorio único (art 111).

De lo mencionado, se interpreta que el sector financiero popular y solidario, se encuentra cubierto por el seguro de depósitos, siempre y cuando se contabilice como pasivos; es decir valores adeudados a pagarse a los afectados.

En cuanto a las características del Seguro de Depósitos, Ricaurte (2007), señala que es explícito y limitado, porque define las obligaciones de sus socios para brindarles una protección, por lo que se requiere de un organismo del Estado eminentemente estructurado y en correcto funcionamiento, apoyado en un marco sólido de regulación y supervisión bancaria; es decir, es un sistema que requiere un apoyo sobre normas de regulación y supervisión básicamente para contribuir en la estabilidad del país. El mismo debe ser limitado y oneroso, por cuanto, dispondrá el alcance de los recursos para cubrir las obligaciones suficientes en función de la cobertura a ambas partes.

Según la información publicada en el portal web de la COSEDE (2015), el Seguro de Depósitos surge a partir del feriado bancario (1998 - 1999) debido a las experiencias por la pérdida del patrimonio de las entidades financieras por las dificultades económicas, lo cual generó un impacto en los depositantes provocando desconfianza.

\section{Naturaleza jurídica del Seguro de Depósitos}

En Ecuador, el seguro de depósitos o fondo de garantía de depósitos. Según el documento realizado por el Foro de Estabilidad Financiera (2001) se define que es concebido como un sistema de protección al ahorro y cuyos objetivos principales son dos: contribuir a la estabilidad del sistema financiero de un país y ante la quiebra de una institución financiera proteger de la pérdida de sus depósitos a los pequeños depositantes que son los que por lo general tienen menor conocimiento financiero.

Es una herramienta que busca proteger los dineros o depósitos de los depositantes, cuenta ahorrista y acreedores, es decir resuelve problemáticas y necesidades de la sociedad y sobre todo brinda estabilidad al sistema financiero popular y solidario.

Bergara (1998) en su obra exteriorizó características propias del seguro de depósitos. Por tanto, una naturaleza jurídica distinta a la del contrato del seguro en general, es uno de los elementos imprescindible de la

'Magister en Derecho Empresarial y Tributación. Docente Investigador Titular Auxiliar. Pontificia Universidad Católica del Ecuador. Escuela de Jurisprudencia y Administración de Empresas. Ambato - Ecuador. E-Mail: eparedes@pucesa.edu.ec

2Estudiante. Pontificia Universidad Católica del Ecuador. Escuela de Jurisprudencia. Ambato-Ecuador. E-Mail: bryan.velaniabayas@hotmail.com 
red de seguridad financiera de un país y la forma que adopte depende del origen del mismo, debiendo señalar que en algunos países cumple un rol mucho más amplio que en otros que más bien son limitados y consiste básicamente en uno o varios fondos a ser utilizados en caso de que una institución del sistema financiero privado se torne inviable. Es recomendable tener un sistema de garantía de depósitos que contar con una protección implícita siempre que este se encuentre bien diseñado y especifique claramente las obligaciones de los actores del sistema financiero de un país, el límite y alcance de decisiones, las características del seguro de depósitos y su funcionamiento.

\section{Derechos de los socios al pago del Seguro de Depósitos}

En la legislación ecuatoriana, el Código Orgánico Monetario y Financiero reconoce el derecho al pago del seguro de depósitos, cuando las entidades financieras del sector popular y solidario, han sido liquidadas por el incumplimiento a la ley, reglamentos y estatutos.

En ese contexto, el Código Orgánico Monetario y Financiero (2018), en el artículo 329 menciona que: "Se hará efectivo a partir de la fecha de notificación de la resolución con la declaratoria de liquidación forzosa de las entidades de los sectores financieros privado y popular y solidario, por parte del organismo de control a la Corporación del Seguro de Depósitos, Fondo de Liquidez y Fondo de Seguros Privados" (Código Orgánico Monetario y Financiero, 2018, art. 329).

Es decir, que en el momento que una entidad que forma parte del sector popular y solidario entra en liquidación forzosa, el Estado a través de la Superintendencia de Economía Popular y Solidaria tiene la obligación de hacer efectivo este derecho tanto a las personas jurídicos como naturales. Por lo tanto, si la liquidación no se efectúa de manera pertinente y ágilmente este derecho vulnera el marco jurídico.

El Código Orgánico Monetario y Financiero (2018), en los artículos 79 y 80 contempla que la COSEDE: "es una persona jurídica de derecho público, no financiera, con autonomía administrativa y operativa" y entre las principales funciones está la de administrar el Seguro de Depósitos de los sectores financiero privado y del popular y solidario y los aportes que lo constituyen, administrar el Fondo de Liquidez del sector antes mencionado, pagar el Seguro de Depósitos, enajenar los activos y derechos adquiridos por la aplicación.

\section{Principio de eficiencia de la Administración Pública}

Es un principio constitucional y legal reconocido en la Constitución de la República del Ecuador en su artículo 227, el mismo que manifiesta que: "La administración pública constituye un servicio a la colectividad que se rige por los principios de eficacia, eficiencia, calidad, jerarquía, desconcentración, descentralización, coordinación, participación, planificación, transparencia y evaluación" (Constitución de la República del Ecuador, 2008, art. 227).

Según Gardais (2002), el principio de eficiencia implica un menor gasto, con la finalidad de cumplir los objetivos del Estado mediante un control jurídico de la administración. De tal manera, representa la efectividad y pertinencia en los servicios brindados con un gasto menor para la administración en cumplimiento de las obligaciones u objetivos. El principio de eficiencia obliga al Estado y a los servidores públicos a trabajar con responsabilidad en el ejercicio de sus funciones en beneficio de la sociedad a fin de brindar buena calidad y servicio en sus funciones; además implica obtener mejores resultados con el mayor ahorro posible de costos, recursos, técnicos y económicos, tanto para el Estado como para los ciudadanos.

Entidades financieras del sector popular y solidario en el Ecuador Conforme la Ley Orgánica de Economía Popular y Solidaria (2017) en artículo 78, señala que: "Para efectos de la presente Ley, integran el Sector Financiero Popular y Solidario las cooperativas de ahorro y crédito, entidades asociativas o solidarias, cajas y bancos comunales, y cajas de ahorro" (Ley Orgánica de Economía Popular y Solidaria, 2017, art. 78).
Sobre las cooperativas de ahorro y crédito, se determinó que este sector se ha conformado por agrupaciones de obreros, comerciantes, productores, artesanos entre otros, con el fin u objetivo de desarrollar una actividad económica en beneficio del sistema financiero. En ese contexto se institucionaliza el sector cooperativo en función de los principios cooperativos: solidaridad, ayuda mutua y bienestar común, buscando el emprendimiento social de sus miembros (Ipiales, 2015). Es decir, estas instituciones tratan de mejorar la economía popular y solidaria y resucitar el espíritu de solidaridad de un pueblo.

Se establece que es una organización empresarial conformada por un conjunto de socios de manera voluntaria, con el fin de desarrollar una actividad o negocio económico en provecho propio para resolver los intereses socioeconómicos, por ende, son instituciones que a través de la organización y administración buscan la ayuda mutua.

Son aquellas que brindan un servicio de intermediación financiera, como recibir depósitos, ahorros o realizar préstamos y su objetivo se enmarca en la filosofía del cooperativismo para financiar proyectos, ya que se enfoca en ayudar a sus socios en los servicios financieros.

Por otra parte el artículo derogado por la Ley Orgánica de Economía Popular y Solidaria (2014), manifiesta que, las entidades asociativas o solidarias, cajas y bancos comunales y cajas de ahorro: Son organizaciones que se forman por voluntad de sus socios y con aportes económicos que, en calidad de ahorros, sirven para el otorgamiento de créditos a sus miembros, dentro de los límites señalados por la Superintendencia de conformidad con lo dispuesto en la presente Ley. También se consideran como parte de estas entidades, aquellas organizaciones de similar naturaleza y actividad económica, cuya existencia haya sido reconocida por otras instituciones del Estado" (art. 104).

\section{Metodología}

La investigación se desarrolló desde un paradigma crítico propositivo porque analizó la teoría y la normativa en torno al fenómeno jurídico que es el cierre de entidades financieras del sector popular y solidario y su incidencia en la vulneración del derecho al pago de depósitos. Para ello, se efectuó un modelo cualitativo, ya que se obtuvo datos cuantificables respecto a las diez entidades financieras del sector financiero popular y solidario con más pasivos a pagar en el Ecuador. Adicionalmente se empleó fuente primaria y secundaria; mismas que permitieron dar sustento a la presente investigación.

Posteriormente, para la recolección de la información se aplicaron entrevistas a abogados especialistas en materia cooperativa y a funcionarios del sector financiero popular y solidario; los cuales aportaron de gran forma con sus conocimientos fundamentados en su profesionalismo y en la práctica habitual de su trabajo.

\section{Resultados}

Las entidades de control: SEPS y COSEDE, carecen de normativa y de procedimientos para el reembolso de los dineros a los afectados, por lo que se recomienda un estudio amplio sobre su naturaleza.

Las entidades financieras del sector popular y solidario en el Ecuador, con mayores afectados en cuanto al monto de devolución del seguro de depósitos, de acuerdo a la información que consta en la COSEDE (2018) son: Coopera Ltda. en liquidación, Acción Rural Ltda. en liquidación, Ejército Nacional en liquidación y Escencia Indígena Ltda. en liquidación, cuyos afectados ascienden a 201.976 personas, conforme se presenta la tabla 1 
Tabla 1. Ranking del pago del seguro de depósitos según la entidad en liquidación y el número de personas afectadas por liquidación de entidades financieras del sector popular y solidario. Al 31 de julio de 2018

\begin{tabular}{|c|c|c|c|}
\hline Entidad en Liquidación & $\begin{array}{l}\text { Monto previsto por } \\
\text { Seguro de Depósitos }\end{array}$ & Beneficiarios & $\begin{array}{c}\% \\
\text { Participación }\end{array}$ \\
\hline COOPERA LTDA, EN LIQUIDACIÓN & 10.261.177 & 126.778 & $22 \%$ \\
\hline ACCION RURAL LTDA EN LIQQUIDACION & 7.861 .658 & 46.215 & $17 \%$ \\
\hline EJERCITO NACIONAL EN LIQUIDACION & 4.671 .784 & 8.586 & $10 \%$ \\
\hline ESCENCIA INDIGENA LTDA EN LIQUUIDACION & 4.529 .097 & 20.397 & $10 \%$ \\
\hline CHOCO TUNGURAHUA RUNA LTDA. EN LIQUUDACIÓN & 3.420 .263 & 17.132 & $7 \%$ \\
\hline LOJA INTERNACIONAL LTDA. EN LIQUUIDACIÓN & 1.572 .882 & 3.290 & $3 \%$ \\
\hline CÁMARA DE COMERCIO DE LOJA ITDA. EN LIQUUIDACIÓN & 1.517 .930 & 9.273 & $3 \%$ \\
\hline CACPET TUNGURAHUA EN LIQUIDACION & 734.991 & 7.718 & $2 \%$ \\
\hline MAESTROS ASOCIADOS DE IMBABURA LTDA EN LIQQUIDACION & 672.109 & 905 & $1 \%$ \\
\hline AMAZONAS LTDA. EN LLQQUIDACION & 660.657 & 24.740 & $1 \%$ \\
\hline NUEVOS HORIZONTES LOJA LTDA. EN LLQQUIDACION & 643.459 & 4.622 & $1 \%$ \\
\hline COFEM LTDA, EN LIQUUIDACIÓN & 552.404 & 4.876 & $1 \%$ \\
\hline PAKARYMUY - AMANECIENDO EN LIQUIDACION & 425.135 & 7.347 & $1 \%$ \\
\hline OTRAS COOPERATIVAS & 9.147 .982 & 155.826 & $20 \%$ \\
\hline TOTAL & 46.671 .527 & 437.705 & $100 \%$ \\
\hline
\end{tabular}

Fuente: COSEDE: Publicaciones Estadísticas Mensuales julio 2018

La provincia con el mayor número de entidades financieras del sector popular y solidario en liquidación es Tungurahua, siendo Ambato el cantón a nivel nacional más afectados, entre los principales motivos del cierre de las entidades, de acuerdo a la información recopilada de Pérez (2018) están: mala administración del sistema financiero y quiebras. En la tabla 2 se muestra la información por provincias en cuanto a las entidades en mención:

Tabla 2. Ranking de COAC en liquidación en el Ecuador por número de entidades

\begin{tabular}{|c|c|}
\hline Provincia-Cantón & $\begin{array}{r}\text { Número } \\
\text { de organizaciones }\end{array}$ \\
\hline TUNGURAHUA & 54 \\
\hline Ambato & 42 \\
\hline Quero & 2 \\
\hline San Pedro de Pelileo & 8 \\
\hline Santiago de Píllaro & 2 \\
\hline PICHINCHA & 31 \\
\hline Mejía & 2 \\
\hline Puerto quito & 1 \\
\hline Quito & 25 \\
\hline Rumiñahui & 3 \\
\hline CHIMBORAZO & 22 \\
\hline Alausí & 1 \\
\hline Colta & 3 \\
\hline Guamote & 6 \\
\hline Riobamba & 12 \\
\hline LOJA & 15 \\
\hline Loja & 12 \\
\hline Macara & 1 \\
\hline Paltas & 1 \\
\hline Saraguro & 1 \\
\hline AZUAY & 14 \\
\hline Camilo Ponce Enríquez & 2 \\
\hline Cuenca & 10 \\
\hline Nabón & 2 \\
\hline СОTOPAXI & 14 \\
\hline Latacunga & 9 \\
\hline Pujilí & 3 \\
\hline Salcedo & 2 \\
\hline GUAYAS & 12 \\
\hline Daule & 1 \\
\hline Guayaquil & 9 \\
\hline Milagro & 2 \\
\hline OTRAS PROVINCIAS & 42 \\
\hline Total & 204 \\
\hline
\end{tabular}

Fuente: SEPS: Catastro del Sector Financiero: Organizaciones en Liquidación. Corte al 09-10-2018
Es decir, constan 204 entidades financieras del sector popular y solidario en liquidación cuyos afectados ascienden a 437.705 personas. Lo mencionado, pone en cuestionamiento la administración pública conformada por la Superintendencia de Economía Popular y Solidaria y la COSEDE, porque no brindan un servicio eficaz y de calidad al sector financiero popular y solidario conformado por entidades financieras, por el no cumplimiento del derecho al pago del seguro de depósitos producto de una liquidación forzosa paupérrima, lo cual no garantiza la ejecución del principio de eficiencia de la administración pública reconocido en la Constitución de la República del Ecuador, art. 227.

El derecho al pago del Seguro de Depósitos, es un avance dentro del sector cooperativo, ya que permite que los cuenta ahorristas puedan recuperar sus depósitos efectuados en entidades financieras (cooperativas); con el fin que no exista un riesgo. Es decir, en buen romance, precautela o salvaguarda los intereses de los interesados.

En ese contexto, este seguro de depósitos es nuevo, ya que no tiene más de 5 años, el mismo que trata de cubrir los riesgos de los depositantes, cuando la cooperativa quiebra o entra en liquidación ese seguro devuelve el dinero depositado.

Por otra parte, debe aumentarse el seguro de depósitos porque básicamente; cuando existe un siniestro se busca ejecutar todas las acciones para devolver los dineros a los depositantes en función de las cuentas de pago y de los segmentos.

De acuerdo al Código Orgánico Monetario y Financiero en su artículo 328 y su disposición transitoria décima cuarta, señala que, el monto protegido por el Seguro de Depósitos para cada persona natural o jurídica, será diferenciado por cada uno de los sectores financieros asegurados; para el sector financiero privado (Bancos) es de hasta US\$ $32.000,00$ y para el sector financiero popular y solidario (cooperativas y mutualistas) se divide por segmento 1 hasta US\$32.000,00, segmento 2 hasta US\$11.290,00, segmento 3 hasta US $\$ 5.000,00$, segmento 4 hasta US\$1.000,00 y segmento 5 hasta US\$1.000,00. En la tabla 3 y 4 se muestra la información en mención:

Tabla 3. Cobertura del Seguro de Depósitos del Sector Financiero Privado

\begin{tabular}{lc}
\hline Segmento & Monto \\
\hline Sector Financiero Privado & hasta \\
(Bancos) & US\$32.000,00 \\
\hline
\end{tabular}

Fuente: COSEDE: Pago del Seguro de Depósitos Corte al 22-10-2018

Tabla 4. Cobertura del Seguro de Depósitos del Sector Financiero Popular y Solidario

\begin{tabular}{ll}
\hline Segmentos & Monto \\
\hline Segmento 1 & hasta US\$ $32.000,00$ \\
Segmento 2 & hasta US $\$ 11.290,00$ \\
Segmento 3 & hasta US $\$ 5.000,00$, \\
Segmento 4 & US\$ $1.000,00$. \\
Segmento 5 & US\$ $1.000,00$.
\end{tabular}

Fuente: COSEDE: Pago del Seguro de Depósitos Corte al 22-10-2018

El Foro de Estabilidad Financiera (2001), señala que, los seguros de depósitos se rigen por el instrumento legal de su creación cuando son explícitos, algún país tiene un sistema de protección implícita, que surge cuando los depositantes y otros acreedores esperan que el Estado brinde protección en caso que una institución financiera cierre sus puertas por haber caído en insolvencia, su financiamiento es discrecional y depende de la habilidad de los gobiernos para disponer del presupuesto público.

La situación de cuenta ahorristas con respecto del derecho al pago del Seguro de Depósitos, no cubre el anhelo de los depositantes porque el seguro no es suficiente para cubrir los riesgos; sin embargo, en muchos de los casos es complicado, porque se generan distorsiones en 
cuanto a la información, pero se tiene conocimiento que existen colectivos que buscan recuperar sus dineros o fondos producto del cierre de las entidades financieras del sector popular y solidario.

\section{Conclusiones}

En función del tratamiento de los datos mencionados cabe señalar que constan 204 entidades financieras del sector popular y solidario en liquidación cuyos afectados ascienden a 437.705 personas. Lo mencionado, pone en cuestionamiento la administración pública conformada por la Superintendencia de Economía Popular y Solidaria y la COSEDE, porque no brindan un servicio eficaz y de calidad al sector financiero popular y solidario conformado por entidades financieras, por el no cumplimiento del derecho al pago del seguro de depósitos producto de una liquidación forzosa paupérrima, lo cual no garantiza la ejecución del principio de eficiencia de la administración pública reconocido en la Constitución de la República del Ecuador, art. 227.

Uno de los problemas determinados consiste en que las entidades de control: Superintendencia de Economía Popular y Solidaria (SEPS) y Corporación del Seguro de Depósitos, Fondo de Liquidez y Fondo de Seguros Privados (COSEDE), no cuentan con el respaldo del ordenamiento y tampoco de medios que permitan devolver con mayor agilidad los depósitos a los afectados, lo cual vulnera derechos constitucionales como el de propiedad y tutela efectiva; y, principios como la inmediación, celeridad, eficiencia y eficacia de la Administración Pública.

Por medio de las entrevistas realizadas a abogados especialistas en materia cooperativa y a funcionarios del sector popular y solidario, se determinó que para el cumplimiento del derecho al pago del seguro de depósitos, se efectúan diferentes procedimientos para su devolución, uno de ellos es el proceso de liquidación forzosa, por cuanto, según lo expuesto en la presente investigación se concluye que, las herramientas proporcionadas por la Superintendencia de Economía Popular y Solidaria (SEPS) respecto al cierre de las entidades financieras son insuficientes e ineficaces, ya que no le conceden al liquidador, funciones para exigir de otros organismos gubernamentales como: Servicio de Rentas Internas, Instituto Ecuatoriano de Seguridad Social, Agencia Nacional de Tránsito, Municipios, entre otros; una atención preferencial y eficiente, que permita disminuir el tiempo del proceso de liquidación, lo cual contribuiría para que las acreencias de los afectados sean devueltas con mayor agilidad.

Se establece que el proceso de liquidación forzosa es complejo, por lo que requiere de personal experimentado a fin de cumplir con los tiempos establecidos en la normativa (4 años como máximo), pero que en la práctica no se cumple, por las diversas funciones y dificultades que tiene el liquidador, como por ejemplo: los bienes no se rematan en los tiempos establecidos debido a la falta de posturas, lo cual imposibilita recuperar el dinero para la devolución de los dineros; la prelación de pagos en la liquidación forzosa, es otro limitante para que los afectados puedan cobrar sus acreencias en el tiempo legal; los que se adeuden a los trabajadores por remuneraciones, indemnizaciones, utilidades, fondos de reserva y pensiones jubilares con cargo al empleador, también resta liquidez para que los depósitos sean devueltos a todos los acreedores.

Otra de las dificultades que atraviesa el proceso de liquidación es la capacidad operativa de los liquidadores, ya que: tienen muchas responsabilidades legales, administrativas financieras, contables; la mayoría desempeña funciones de liquidador de varias entidades; y, en varios casos, desarrollan otras actividades económicas, lo cual implica que el proceso en mención se demore más tiempo del permitido por la ley. Se establece que se ha vulnerado el derecho al pago del seguro de depósitos consagrado en el Art 329 del Código Orgánico Monetario y Financiero (2018), por cuanto, hasta el 9 de octubre del 2018, de acuerdo a la información recopilada de la SEPS existen 204 entidades financieras del sector popular y solidario, en liquidación; lo mencionado repercute en que las entidades financieras del sector popular y solidario, con mayores afectados en cuanto al monto de devolución del seguro de depósitos, de acuerdo a la información que consta en la COSEDE (2018) son: Coopera Ltda. en liquidación, Acción Rural Ltda. en liquidación, Ejercito Nacional en liquidación y Escencia Indígena Ltda. en liquidación, cuyos afectados ascienden a 201.976 personas, por lo tanto debería existir un proceso de liquidación pertinente para devolver prontamente los dineros o fondos de las personas involucradas.

Así mismo, la función del seguro de depósitos ha sido analizada de manera teórica y legal, por lo que es un progreso dentro del sector popular y solidario que exista éste seguro, ya que es un mecanismo de contingencia financiera gratuito para la ciudadanía, que protege de forma limitada los depósitos efectuados en las entidades en liquidación forzosa por sus clientes en los términos que señala la ley; considerándose un apoyo legal en beneficio de los afectados.

Este procedimiento permitirá una eficiente devolución de los recursos a los afectados por el cierre de las entidades del sector popular y solidario, el mismo que debe empezar con la resolución de liquidación emitida por la Superintendencia de Economía Popular y Solidaria (SEPS), indicando las causales según el artículo 303 del Código Orgánico Monetario y Financiero (COMYFI). Luego, se designa un liquidador por la Asamblea General de la Cooperativa y la SEPS dentro del término de quince días. Posteriormente, existe la aceptación por parte del liquidador, misma que no es una obligación, en caso de designación; el liquidador realiza un operativo de liquidación (ir a la cooperativa). Por consiguiente se determina la publicación en un diario de amplia circulación en el domicilio principal de la cooperativa en liquidación y de las sucursales, si las hubiere para que el liquidador levante los estados de liquidación y la información de cartera de créditos; construye la base de datos de los activos y pasivos. Para por último realizar el proceso de ejecución judicial y extrajudicial para el proceso de pago en función de la prelación de pagos conforme el artículo 315 del COMYFI.

El procedimiento de liquidación debe sujetarse a un tiempo de hasta 2 años con la finalidad de dar continuidad a los procesos y el tiempo suficiente para no generar un impacto social, económico y jurídico en los depositantes en el Ecuador.

\section{Referencias}

Bergara, M. (1998). Hacia la Explicación de un Fondo de Garantía para el Sistema Bancario Uruguayo, Montevideo, Centro Mundial de investigación para la Paz, Universidad para la Paz.

Cerna, L. (2015). Metodología de análisis económico y social para procesos de resolución en cooperativas de ahorro y crédito del segmento 3 y 4, utilizando la estrategia de exclusión de activos y de pasivos. Recuperado de http:// repositorio.uasb.edu.ec/bitstream/10644/4515/1/T1636-MFGR-Cerna-Metodologia.pdf

Código Orgánico Monetario y Financiero (2018). Ecuador: Corporación de Estudios y Publicaciones.

Corporación del Seguro de Depósitos, Fondo de Liquidez y Fondo de Seguros Privados (COSEDE): Publicaciones Estadísticas Mensuales julio 2018 PEM. Recuperado en 24 de septiembre de 2018, de http://www.cosede.gob.ed/ publicaciones-estadisticas-pem/

Ecuador. Leyes y Decretos. (s.f). Constitución de la República del Ecua- 
dor. 1e. Quito: Ecuador.

Foro de Estabilidad Financiera, Guía para el Desarrollo de Sistema Efectivos de Seguro de Depósitos, México, 2001.

Garabiza, B. (2014). El rol de la red de seguridad financiera, los seguros de depósitos y su importancia para la estabilidad financiera ecuatoriana: periodo 2007-2013. Recuperado de http://repositorio.ug.edu.ec/bitstream/redug/6275/1/TES/S\%20BELLA\%20GARABIZA\%20CASTRO\%20\%20final.pdf

Gardais, G. (2002). El control de legalidad y la eficiencia y eficacia como principios jurídicos fiscalizables. Revista de derecho de la Universidad Católica de Valparaíso.

Ipiales, A. (2016). El Seguro de Depósitos en el sector financiero popular y solidario, y su incidencia en los depositantes del Ecuador, año 2015. Recuperado de http://www.dspace.uce.edu.ec/bitstream/25000/9143/1/T-UCE-0013Ab-443.pdf

Navarro, D. (2015). Análisis de la participación del sector bancario privado como herramienta para el crecimiento económico del país periodo: 20112014. Recuperado de http://repositorio.ug.edu.ec/bitstream/redug/8757/1/ TESIS\%2ODANILO\%2ONAVARRO\%20docx\%202.pdf

Pérez, A. (2018). Un dominó de quiebras. Revista Vistazo, págs. 26-27-29.

Reglamento a la ley Orgánica. Solidaria y del Sector Financiero Popular Y Solidario (2017). Ecuador: Corporación de Estudios y Publicaciones.

Ricaurte, M. (2007). El seguro de depósitos en el Ecuador. Quito, EC: Universidad Andina Simón Bolívar, Sede Ecuador.

Superintendencia de Economía Popular y Solidaria. Catastro del Sector Financiero. Recuperado en 24 de septiembre de 2018, de https://servicios.seps. gob.ec/gosf-internet/paginas/consultarOrganizaciones.jsf 